\title{
Tick Borne Relapsing Fever Imported into the United Kingdom
}

\author{
Maj J W Simon, \\ MA MRCP DTMGH \\ *Senior Specialist in Medicine, Cambridge Military Hospital, Aldershot, Hants
}

\begin{abstract}
SUMMARY: A case of tick borne relapsing fever contracted in Cyprus and imported into England is reported. This is the first report of the diagnosis being established by finding the organism in the bone marrow.
\end{abstract}

\section{Case Report}

- A 24 year old soldier was admitted to the Cambridge Military Hospital, Aldershot, with a two-day history of fever, vomiting, headache and backache of abrupt onset. He had had a similar episode which lasted three days and ended five days before the start of his current illness. He I had recently returned directly to England from Cyprus, where he had spent three weeks on exercise. In the last week of this exercise, and seven days before he first became ill, he spent the night in a cave, and on waking noted the presence of ticks on his legs.

On examination his temperature was $38.3^{\circ} \mathrm{C}$. The liver was palpable, but not tender, $2 \mathrm{cms}$ below the right costal margin. The spleen was palpable $3 \mathrm{cms}$ below the left costal margin. A fading haemorrhagic lesion, possibly an , insect bite, was present over the Achilles tendon of the left leg and there were no other abnormal findings.

Investigations showed $\mathrm{Hb} 10.4 \mathrm{~g} / \mathrm{dl}, \mathrm{MCV} 90 \mathrm{fl}, \mathrm{PCV}$ $0.34, \mathrm{MCHC} 30 \mathrm{~g} / \mathrm{dl}, \mathrm{MCH} 30 \mathrm{pg}$. The white cell count was $7.7 \times 10^{9} / 1$ with 25 per cent polymorphs, 65 per cent lymphocytes and 7 per cent monocytes. The platelet count was $97 \times 10^{9} / 1$. The erythrocyte sedimentation rate (ESR) was $90 \mathrm{~mm} /$ hour.

Three hours after admission his temperature rose to $41^{\circ} \mathrm{C}$ and he had a rigor. The following tests were negative 1- cultures of urine, sputum and blood; repeated examination of the peripheral blood for malarial parasites; Weil Felix and Widal tests and serological tests for syphilis, glandular fever, psittacosis, $Q$ fever, toxoplasmosis, cytomegalovirus, leptospirosis, brucellosis and hepatitis B. Liver function tests, urea and electrolytes, prothrombin time and immunoglobulins were normal apart from IgM which was $5.53 \mathrm{~g} / \mathrm{l}$ (normal $0.45-1.8$ ) consistent with acute infection. A chest X-ray, electrocardiogram and ultrasound of the liver and biliary tract were normal.

After one day he became apyrexial and asymptomatic and remained thus for three days, following which there was recurrence of symptoms and fever up to $41^{\circ} \mathrm{C}$ for two days. There was then an apyrexial asymptomatic period of five days followed by a recurrence lasting two Idays. Physical signs remained unchanged throughout this period, at the end of which $\mathrm{Hb}$ was $9.6 \mathrm{~g} / \mathrm{dl}$ with a nor- mochromic normocytic film. The white cell count and differential platelet count, liver function tests and urea and electrolytes were normal. The ESR was $66 \mathrm{~mm} /$ hour. A specimen of bone marrow was obtained by sternal puncture. This showed normoblastic erythropoiesis and the presence of organisms of the genus Borrelia. These were also present, though in sparser number, in a Giemsa stained peripheral blood smear taken at the same time.

The patient was given $30 \mathrm{mg}$ of prednisolone orally followed 24 hours later by a single oral dose of $200 \mathrm{mg}$ of doxycycline. Two hours after this he felt nauseous and his pulse rate rose from 80 to 100 per minute, and remained thus for two hours. He remained otherwise well and there was no change in blood pressure or temperature. He stayed in hospital for a further 16 days and was discharged 39 days after admission, at which time neither the spleen nor the liver was palpable. At discharge $\mathrm{Hb}$ was $13.4 \mathrm{~g} / \mathrm{dl}$ and white cell count, platelets and ESR were normal.

Two weeks later he was readmitted with symptoms and signs, similar to, but of a milder nature than his other relapses. Borrelia were not found on a peripheral blood smear. It was assumed that he had suffered a further relapse and he was given a one week course of tetracycline $250 \mathrm{mg}$ q.d.s. without ill effect. There was no further relapse over a period of six months follow up. The course of events is show in Figure 1.

\section{Discussion}

As a disease imported into Great Britain relapsing fever is rarely recognised. Only two cases were notified in the decade 1972-1982. ' The patient contracted the disease

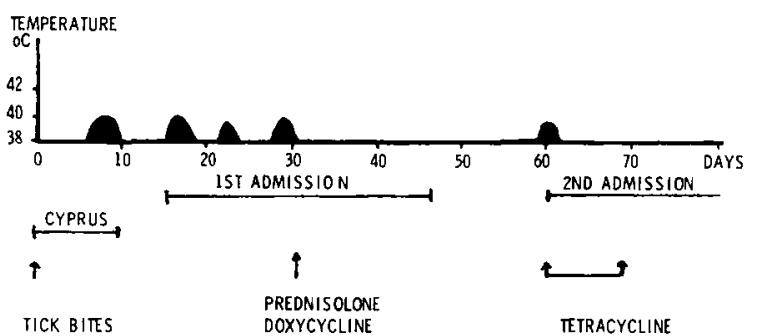

(FIGURE 
after a night spent in a cave in a rural area near Nicosia in Cyprus where he was bitten by ticks. He appears to have had a mild illness and indeed tick borne relapsing fever (TBRF) in Cyprus is rarely severe. ${ }^{2}$ Relapsing fever was first diagnosed in Cyprus in $1939 .{ }^{2}$ It has since been identified in most parts of Cyprus especially in the rural areas around Kyrenia, Famagusta, Nicosia and Larnaca. Several cases were reported in British soldiers in $1945 .^{3}$ All had slept in a cave $8-9$ days before becoming ill. The vector was shown to be the soft tick Ornithodorus tholazani which lives in caves, holes and rodent burrows. ${ }^{2}$ In Cyprus it prefers rocky shelters and caves with guano floors. It feeds for less than an hour and the bite is rarely painful. Infection occurs by irrigation of the feeding puncture with contaminated saliva or coxal fluid. Ticks can act as the reservoir of infection by the mechanism of transovarial passage. ${ }^{4} \mathrm{~A}$ presumed rodent reservoir in Cyprus has not been identified. ${ }^{2}$ The disease is infrequently diagnosed in the indigenous population - probably because previous exposure leads to acquired immunity. It is well known that in endemic areas the disease is usually more severe in newcomers. ${ }^{5}$ The causative organism in Cyprus has not been clearly identified - it is either Borrelia hispanica or Borrelia persica or possibly both. ${ }^{2}$

The estimated incubation period in this case was 7 days which is the average found in a review of 2073 cases. The average number of relapses in TBRF is 3 with a range of $0-13{ }^{6}$ This patient had 4 relapses. Relapses are due to the antigenic instability of the organism. ${ }^{7}$ Relapses stop when the patient develops cumulative immunity to the relapse strains. ${ }^{8}$ The abrupt onset of the initial illness, and of each relapse, whilst feeling well between relapses, which occurred in this patient, are characteristic. Relapses tend to be less severe than the initial illness. In this patient relapses were of equal clinical severity apart from the last relapse which was milder. Apart from splenomegaly, which occurs in 41 per cent, and hepatomegaly ( 18 per cent) this patient had no other signs of TBRF such as jaundice ( 8 per cent), rash ( 28 per cent) and neurological features ( 8 per cent). ${ }^{6}$ Moderate normochromic normocytic anaemia is common. ${ }^{6}$ The absolute white cell count was normal but there was relative lymphocytosis and an absolute monocytosis. Monocytosis up to 10 per cent of the total white cell count is well documented. ${ }^{9}$ In this case there was an initial thrombocytopenia. Thrombocytopenia occurs in 93 per cent of cases of louse borne relapsing fever (LBRF) but figures for TBRF are not available. ${ }^{10}$ The ESR is markedly variable. ${ }^{11}$

In this patient Borrelia were first found during the third relapse on examination of the bone marrow. Organisms were also present, though in sparse number, in blood films made at the same time as, and for one day after, the bone marrow examination. They were not found on reexamination of earlier peripheral blood films. A literature search suggests this is the first report of finding the organism in the marrow. In all types of relapsing fever the organism is rarely found in the blood in intervals beween relapses, although during febrile periods it can found in 70 per cent of cases. There are, however, solke types of relapsing fever where the laboratory diagno $\overrightarrow{\mathrm{g}} \mathrm{s}$ is hampered by the paucity of organisms in the blood In such a case the diagnosis can often be made serologically or by inoculation of blood into young mice. ${ }^{12}$ Borre $3 a$ may be difficult to detect with Romanovsky stains a a recent study using an acridine-orange stain and fluoresscent microscopy has provided a higher diagnostic yieldệ 3 It is possible that bone marrow examination will provide an alternative diagnostic method when examination df the peripheral blood is negative. Serological testing for $B$.hispanica and B.persica was not possible due to laek of specific antigen.

This patient did not show the characteristic features of a Jarisch-Herxheimer reaction (JHR) after treatme $\overrightarrow{b b}$ and the small dose of prednisolone he was given wags unlikely to have influenced this as much larger doses $(3 \mathrm{mg} / \mathrm{kg})$ had only a slight effect in modifying the in LBRF. ${ }^{14}$ The JHR is thought to be due to an endêftoxinaemia and may be modulated by a secondary retoase of opioid peptides. ${ }^{15,16}$ Meptazinol 300-500mg intravenously has recently been shown to diminish ord vent the JHR or LBRF whilst naloxone $30-40 \mathrm{mg}$ 䆜- 1 travenously had no effect. ${ }^{17}$

This patient was initially treated with a single $200 \mathrm{mg}$ dose of doxycycline and had one further repepse 4 weeks later. This dose had been very successfully issed in the treatment of LBRF. ${ }^{18}$ TBRF however is kno be more likely to relapse after treatment and trials needed to compare tetacycline with single dose dogycycline. Until then a prolonged course of tetracyclige remains the treatment of choice in TBRF. ${ }^{19}$

\section{REFERENCES}

1. Office of Population, Censuses and Surveys and $\mathrm{PH} \underset{\mathrm{F}}{\mathrm{S}}$ Communicable Disease Centre. Series MB2 No 9 Communicable Disease Statistics. 1982; Table $1 \mathrm{~A}$.

2. GAMBLES, R M, COCHHLL. N F. Relapsing fever in Cypr Ann Trop Med Parasitol 1984; 42: 228-302.

3. Wood, R C, Dixon, K C. Tick borne relapsing fever Cyprus. Brit Med J 1945; 2: 526.

4. DutTon, J E, Todd, J L. Brit Med J 1905; 2: 1295 . @

5. WatTon, G. Symp Roy Zool Soc London 1962; 6: 83-15.

6. SOUTHERN, P M, SANFORd, J P. Relapsing fever-a clinikal and microbiological review. Medicine 1969; 48(2): 129.149.

7. Stoenner H G, Dodd, T, Larsen C. J Exp Med 198; 156(5): 1297-1311.

8. JUdGE, D M. Am J Trop Med Hyg 1974; 23(5): 957-96․

9. Quin, C E , Perkins, E S. East Afr J Trop Med Hyg 198; 49: 30 .

10. AHMED M A. Trop George Med 1980; 32(z): 106-111 $\frac{D}{0}$

11. Charters, A D. Trans Roy Soc Trop Med Hyg 1950; $\mathbf{4}$ : 427.

12. Bohls, S W, Irons J V. Amer Assoc Advance Monograph No 18. 42-48.

13. Sciotto, C G, Lever, B A, White, W L, Istre, G R, Anæh Pathol Lab Med 1983; 107(7): 384-386.

14. Warrell, D A, Pope, H M, Parny, E H O, Perine, P五, Bryceson, A D M. Clin Sci 1970; 39: 123-145. 
15. Wright, D J M. Parasite immunology 1980; 2: 201-221.

16. Wright, D J M. Neuropeptides 1981; 1: 182-202.

17. Teklu, B, Habte-Michael A, Warkell, D A, White, N J, Wright, D J M. Lancet 1983; 835-839.
18. Perine, P L, Awoke, S, Krause, D W, McDade, J E. Lancet $1974 ; 742-744$.

19. Warrell, D A, Perine, P L, Krause, D W, Bmg, D H, MacDougal, S J. Infect Dis 1983; 147(5): 898-909. 